\title{
A relação profissional-paciente. O entendimento e implicações legais que se esta- belecem durante o tratamento ortodôntico
}

\author{
Rodolfo Francisco Haltenhoff Melani* ${ }^{\star}$ Ricarda Duarte da Silva**
}

\section{Resumo}

Objetivo: investigar a relação profissional/paciente na área da Ortodontia. Foram analisados os aspectos legais que permeiam o tratamento ortodôntico. Metodologia: a pesquisa foi realizada por meio de dois questionários: um dirigido a 10 profissionais da área de Ortodontia e o outro dirigido a 100 pacientes em tratamento ortodôntico dos respectivos profissionais. Resultados: a análise das respostas obtidas demonstrou que a preocupação estética é a principal motivação que leva os pacientes aos consultórios ortodônticos. Os profissionais acreditam existirem fatores imprevisíveis que podem intervir no desenvolvimento e no resultado do tratamento ortodôntico. Apesar deste fato, $40 \%$ dos profissionais asseguram ao paciente o sucesso do tratamento. Para todos os profissionais, o principal meio de defesa do ortodontista frente a um processo de responsabilidade civil é o prontuário completo. Porém, 90\% dos entrevistados não possuem em seu prontuário a ficha de procedimentos executados, com as intercorrências anotadas e assinatura do paciente, pressupondo o consentimento do tratamento. Nos contratos escritos de honorários e manutenção foi verificado que $50 \%$ dos profissionais formalizavam o registro. Conclusão: concluiu-se que existe uma preocupação em relação à parte financeira, e os profissionais não vêem a correta execução do prontuário principal como um meio de defesa e tampouco preocupam-se em fornecer informações claras e por escrito aos seus pacientes.

Palavras-chave: Ortodontia. Relação profissional-paciente. Aspectos legais.

\section{INTRODUÇÃO}

A relação profissional/paciente envolve, fundamentalmente, três aspectos significativos: a conduta clínica, os aspectos éticos e os parâmetros legais. A preocupação com os aspectos legais tornou-se um assunto relevante a ser abordado, devido à ocorrência de um processo de modificação do comportamento social, que reflete na prática da cidadania. Uma das principais evidências se deve ao fato de que parcela da população passou a ter acesso ao Código de Defesa do Consumidor, adotado em nosso país com a Lei 8.078 , de 11 de setembro de $1990^{4}$.

Os principais conceitos legais relacionados à res-

* Professor Doutor do curso de mestrado em Deontologia e Odontologia Legal da Universidade de São Paulo (USP).

** Aluna do curso de mestrado em Deontologia e Odontologia Legal da Universidade de São Paulo USP. Especialista em Ortodontia e Ortopedia Facial pela Universidade Estadual de Londrina (UEL). 
ponsabilidade civil estão documentados no Novo Código Civil Brasileiro, de maneira objetiva, nos seus artigos: "Art 186 -Aquele que, por ação ou omissão voluntária, negligência ou imprudência, violar direito ou causar prejuízo a outrem, fica obrigado a reparar o dano." e "Art 1.545 - Os médicos, cirurgiões, farmacêuticos, parteiras e dentistas são obrigados a satisfazerem o dano sempre que da imprudência, negligência ou imperícia em atos profissionais, resultar morte, inabilitação de servir ou ferimento" 5 .

Já a atuação do cirurgião-dentista é regulada em esfera administrativa pelo Código de Ética Odontológico, do Conselho Federal de Odontologia, de 19986. Em seu capítulo 7, dá ênfase especial ao relacionamento profissional/paciente. Apesar de pertencer a uma esfera administrativa, o Código de Ética Odontológico reflete, ao ditar as normas de conduta do profissional de Odontologia, abordagens legais.

Esses três instrumentos auxiliam no estabelecimento de uma relação profissional/paciente baseada em direitos e deveres, para que os objetivos do tratamento odontológico sejam atingidos e preservados.

Particularmente, na especialidade da Ortodontia, o estudo da relação profissional/paciente é significativo, pois a preocupação com os aspectos estéticos e a harmonia facial têm levado um grande número de pessoas a buscar tratamento ortodôntico, com expectativas de resultados, muitas vezes, difíceis de serem alcançados.

Simultaneamente, evidenciou-se uma nítida implicação com os aspectos legais do exercício da profissão, advindos de um crescente número de processos de responsabilidade contra os que exercem a Ortodontia no Brasil22.

Trabalhos realizados em âmbito administrativo apontam que o relacionamento profissional/ paciente é o fator motivador mais relevante nas queixas contra os profissionais e não os aspectos técnico-científicos ${ }^{2,9,19}$.

A Odontologia, ao mesmo tempo em que aprofunda a sua produção no campo científico e tecnológico, necessita aprimorar a relação profis- sional/paciente, observando seus reflexos éticos e legais ${ }^{8}$. Neste sentido, destaca-se a Ortodontia, especialidade em que os tratamentos são de longa duração, na qual se estabelece uma estreita relação profissional/paciente, envolvendo uma grande expectativa em relação aos resultados.

O presente estudo buscou analisar questões legais que envolvem a situação do profissional de Odontologia, considerando as particularidades que permeiam a especialidade da Ortodontia, observando aspectos da relação profissional/paciente durante o tratamento, verificando o grau de entendimento entre as partes e os possíveis desdobramentos éticos e legais que podem ocorrer quando essa relação não se estabelece a contento.

\section{MATERIAL E MÉTODOS}

A pesquisa foi realizada por meio de dois questionários: um contendo 25 perguntas dirigidas a profissionais da área de Ortodontia e o outro contendo 15 perguntas dirigidas a pacientes em tratamento ortodôntico. As perguntas foram formuladas com base na literatura. A população objeto do presente estudo foi constituída de especialistas em Ortodontia registrados no Conselho Regional de Odontologia do Estado do Paraná (CRO-PR) e seus respectivos pacientes em tratamento da região de Curitiba-PR. A amostra consistiu de 10 profissionais da área da Ortodontia e 100 pacientes, dos respectivos profissionais.

\section{RESULTADOS}

\section{Resultados relativos aos profissionais}

A tabela 1 mostra a visão do profissional quanto ao que é o mais importante no tratamento ortodôntico: a) 10\% responderam a melhora apenas da estética e b) 90\% a melhora da estética e da função, em conjunto.

A tabela 2 mostra a visão do profissional quanto ao que acreditam ser o mais importante no tratamento ortodôntico para seus pacientes: a) para $40 \%$ dos profissionais a melhora da estética e b) para $60 \%$ a melhora da estética e da função em conjunto. 
Tabela 1 - Dados referentes às respostas do que os profissionais julgam mais importante no tratamento ortodôntico.

\begin{tabular}{ccccc}
\hline & freqüência & percentagem & $\begin{array}{c}\text { percentagem } \\
\text { válida (\%) }\end{array}$ & $\begin{array}{c}\text { percentagem } \\
\text { acumulada }\end{array}$ \\
\cline { 2 - 5 } a & 10 & 10 & $10 \%$ & 10 \\
b & 90 & 90 & $90 \%$ & 100 \\
\hline
\end{tabular}

a) melhora apenas da estética;

b) melhora da estética e da função, simultaneamente.

Tabela 2 - Dados referentes às respostas do que os pacientes julgam mais importante no tratamento ortodôntico.

\begin{tabular}{ccccc}
\hline & freqüência & percentagem & $\begin{array}{c}\text { percentagem } \\
\text { válida (\%) }\end{array}$ & $\begin{array}{c}\text { percentagem } \\
\text { acumulada }\end{array}$ \\
\cline { 2 - 5 } a & 40 & 40 & $40 \%$ & 40 \\
b & 60 & 60 & $60 \%$ & 100 \\
\hline
\end{tabular}

a) melhora apenas da estética;

b) melhora da estética e da função, simultaneamente.

Dos profissionais entrevistados, $20 \%$ asseguram ao paciente o êxito do tratamento ortodôntico e $20 \%$ asseguram o êxito do tratamento de acordo com as expectativas do paciente.

Os profissionais foram unânimes ao afirmarem que fornecem esclarecimentos aos pacientes sobre a execução do tratamento e seus possíveis desdobramentos, $50 \%$ dos profissionais o fazem de forma verbal, $10 \%$ por escrito, $30 \%$ por escrito com assinatura do paciente e $10 \%$ de forma verbal e por escrito com assinatura do paciente.

O tempo de duração do tratamento ortodôntico está entre 2 e 3 anos, baseado na experiência clínica dos profissionais entrevistados, $60 \%$ dos profissionais passam a informação por escrito e $40 \%$ de forma verbal.

Todos os profissionais acreditam existirem fatores imprevisiveis que podem interferir no desenvolvimento e no resultado do tratamento ortodôntico. Entre esses fatores, citam padrão de crescimento $(40 \%)$, anquilose (20\%), traumas (10\%), colaboração do paciente $(80 \%)$ e resposta biológica individual (40\%).

Perguntamos aos profissionais se realizam algum tipo de contrato. A tabela 3 mostra que 70\%
Tabela 3 - Dados referentes às respostas quanto à realização de contrato.

\begin{tabular}{ccccc}
\hline & freqüência & percentagem & $\begin{array}{c}\text { percentagem } \\
\text { válida (\%) }\end{array}$ & $\begin{array}{c}\text { percentagem } \\
\text { acumulada }\end{array}$ \\
\cline { 2 - 5 } $\operatorname{sim}$ & 70 & 70 & $70 \%$ & 70 \\
não & 30 & 30 & $30 \%$ & 100 \\
\hline
\end{tabular}

responderam que sim e 30\% responderam que não realizam nenhum tipo de contrato. Perguntamos para aqueles que realizam contratos qual o teor destes: $50 \%$ realizam contrato de honorários e manutenção, $40 \%$ dos profissionais realizam contrato ressaltando o comprometimento do paciente com o tratamento, $30 \%$ realizam contrato ressaltando o comprometimento do profissional com o tratamento e $10 \%$ ressaltam normas gerais do tratamento em seu contrato.

Para 90\% dos profissionais, responsabilidade profissional compreende dar informações sobre custos, prazos, tempo de tratamento e objetivos de tratamento. Para 70\% é ser responsabilizado por infrações éticas cometidas durante o tratamento. Ter um prontuário adequado com anotações de todas as ocorrências foi citado por $80 \%$ e $70 \%$ dos profissionais definem responsabilidade profissional como sendo o dever de ressarcir o paciente quando causou um dano e foi comprovada sua culpa.

A tabela 4 mostra o que, na opinião do profissional, é o mais importante na relação profissional/paciente: a) 50\% acreditam ser a capacidade técnica o mais importante, b) 30\% acreditam ser prestar esclarecimentos sobre o tratamento e c) $20 \%$ dos profissionais não responderam.

Para 90\% dos profissionais, um bom relacionamento com seu paciente pode impedir uma ação de responsabilidade civil.

Ao serem questionados sobre o que é o mais importante na defesa do profissional frente a um processo de responsabilidade civil, 20\% dos profissionais não souberam responder, para outros $20 \%$ é a presença de um contrato por escrito e $60 \%$ assinalaram a presença do prontuário completo do paciente. 
Tabela 4 - Dados referentes ao que é mais importante na relação profissional-paciente, na visão do profissional.

\begin{tabular}{ccccc}
\hline & frequiência & percentagem & $\begin{array}{c}\text { percentagem } \\
\text { válida (\%) }\end{array}$ & $\begin{array}{c}\text { percentagem } \\
\text { acumulada }\end{array}$ \\
\cline { 2 - 5 } a & 50 & 50 & $50 \%$ & 50 \\
b & 30 & 30 & $30 \%$ & 80 \\
c & 20 & 20 & $20 \%$ & 100 \\
\hline
\end{tabular}

a) capacidade técnica;

b) prestar esclarecimentos sobre o tratamento;

c) não responderam.

Tabela 5 - Dados referentes ao que é mais importante no tratamento ortodôntico para o profissional, na visão do paciente.

\begin{tabular}{ccccc}
\hline & freqüência & percentagem & $\begin{array}{c}\text { percentagem } \\
\text { válida (\%) }\end{array}$ & $\begin{array}{c}\text { percentagem } \\
\text { acumulada }\end{array}$ \\
\cline { 2 - 5 } a & 9 & 9 & $9 \%$ & 9 \\
b & 83 & 83 & $83 \%$ & 92 \\
c & 4 & 4 & $4 \%$ & 96 \\
d & 4 & 4 & $4 \%$ & 100 \\
\hline
\end{tabular}

a) melhora apenas da estética;

b) melhora da estética e da função, simultaneamente;

c) melhora apenas da função;

d) não responderam.

Quando questionados sobre quais os documentos que constituem o seu prontuário, $100 \%$ dos profissionais possuem em seu prontuário documentação ortodôntica básica, que compreende modelos em gesso, fotografias, radiografias e ficha de procedimentos executados, $90 \%$ afirmam possuir a ficha clínica e ter um plano de tratamento em seu prontuário. Entretanto, $80 \%$ não possuem uma ficha de procedimentos executados com intercorrências assinada pelo paciente, 60\% afirmam que o contrato não é parte integrante de seu prontuário e $70 \%$ afirmam que não faz parte de seus registros o consentimento livre e esclarecido. O documento de honorários está presente em 70\% dos prontuários dos profissionais.

\section{Resultados relativos aos pacientes}

Quanto ao gênero dos pacientes entrevistados, $53 \%$ eram do gênero feminino, 39\% do gênero masculino e $8 \%$ não responderam.

A tabela 5 mostra o que os pacientes acreditam
Tabela 6 - Principal expectativa de melhora do paciente, com relação ao tratamento ortodôntico.

\begin{tabular}{ccccc}
\hline & frequiência & percentagem & $\begin{array}{c}\text { percentagem } \\
\text { válida (\%) }\end{array}$ & $\begin{array}{c}\text { percentagem } \\
\text { acumulada }\end{array}$ \\
\cline { 2 - 5 } a & 33 & 33 & $33 \%$ & 33 \\
b & 60 & 60 & $60 \%$ & 93 \\
c & 3 & 3 & $3 \%$ & 96 \\
d & 4 & 4 & $4 \%$ & 100 \\
\hline
\end{tabular}

a) melhora apenas da estética;

b) melhora da estética e da função, simultaneamente;

c) melhora apenas da função;

d) não responderam.

Tabela 7 - Principal motivo que levou o paciente a procurar 0 tratamento ortodôntico.

\begin{tabular}{ccccc}
\hline & frequiência & percentagem & $\begin{array}{c}\text { percentagem } \\
\text { válida }(\%)\end{array}$ & $\begin{array}{c}\text { percentagem } \\
\text { acumulada }\end{array}$ \\
\cline { 2 - 5 } a & 61 & 61 & $61 \%$ & 61 \\
b & 8 & 8 & $8 \%$ & 69 \\
c & 17 & 17 & $17 \%$ & 86 \\
d & 3 & 3 & $3 \%$ & 89 \\
e & 11 & 11 & $11 \%$ & 100 \\
\hline
\end{tabular}

a) melhora apenas da estética;

b) possuir dores faciais;

c) melhora apenas da função;

d) orientação de outro cirurgião-dentista;

e) não responderam.

ser o mais importante no tratamento ortodôntico para seu ortodontista: a) para 9\% a melhora da estética, b) para $83 \%$ a melhora da estética e da função simultaneamente, c) $4 \%$ acreditam que a melhora da função é o mais importante para o profissional e d) $4 \%$ dos pacientes não responderam.

A tabela 6 mostra qual é a expectativa principal do paciente em relação à melhora com o tratamento ortodôntico: a) 33\% responderam que a melhora estética é a sua principal expectativa, b) $60 \%$ esperam a melhora estética e da função em conjunto, c) 3\% tem como expectativa principal a melhora da função e d) 4\% não responderam.

No que concerne a esclarecimentos sobre a forma de desenvolvimento do tratamento e seus possiveis desdobramentos, 95\% afirmaram ter sido esclarecidos. 
Quando questionados se antes de iniciar o tratamento tiveram oportunidade de expressar o que os levou a procurar o tratamento ortodôntico $91 \%$ responderam que sim. Ainda neste contexto, a tabela 7 mostra qual foi o principal motivo que os levou a procurarem o tratamento ortodôntico: a) $61 \%$ afirmaram que foi a preocupação com a estética, b) $8 \%$ afirmaram possuírem dores faciais e por isso procuraram o tratamento, c) $17 \%$ responderam que foi a melhora da função, d) $3 \%$ disseram ter recebido orientação de outro cirurgião-dentista e e) $11 \%$ dos pacientes não responderam.

Perguntamos aos pacientes se haviam assinado algum tipo de documento, $6 \%$ não responderam, 53\% afirmaram ter assinado algum tipo de documento, $41 \%$ afirmaram não ter assinado documento algum.

Ainda relacionado a documentos assinados pelos pacientes, perguntamos do que se tratava: contrato de honorários e manutenção (31\%), documento ressaltando o comprometimento do paciente com o tratamento (21\%), documento ressaltando o comprometimento do profissional com o tratamento (23\%) e documento ressaltando o plano de tratamento (32\%).

O mais importante para o paciente no relacionamento profissional/paciente é, para 59\%, a capacidade técnica, para $5 \%$ o atendimento no consultório, para 15\% dar esclarecimentos é o mais importante no relacionamento profissional paciente e $21 \%$ dos pacientes não responderam.

Perguntamos aos pacientes entrevistados se receberam alguma informação sobre tempo de tratamento: $92 \%$ dos pacientes responderam que sim, $6 \%$ responderam o tempo exato do tratamento, $81 \%$ tiveram como informação um tempo médio de tratamento, $5 \%$ responderam que seu ortodontista afirmou não ser possível dizer o tempo de tratamento e 8\% não responderam.

Perguntamos se a informação de tempo de tratamento foi dada por escrito: $8 \%$ não responderam, $28 \%$ receberam a informação sobre tempo de tratamento por escrito e para $64 \%$ dos pacientes esta informação não foi dada por escrito.
Quando questionados sobre quanto tempo pode durar um tratamento ortodôntico, em média, no seu ponto de vista: $5 \%$ dos pacientes não responderam, $2 \%$ responderam menos de 1 ano, $12 \%$ responderam entre 1 e 2 anos, 53\% entre 2 e 3 anos, 12\% entre 3 e 4 anos, para 1\% mais de 4 anos e $15 \%$ responderam que depende do caso.

\section{DISCUSSÃO}

\section{Expectativas de resultados de tratamento}

$\mathrm{Na}$ Odontologia a preocupação com os aspectos estéticos e com os procedimentos visando a cura são indissociáveis. Portanto, cabe ao cirurgião-dentista a busca do restabelecimento da saúde bucal plena ${ }^{25}$.

O enfoque principal é a especialidade de Ortodontia, na qual um grande número de pacientes tem expectativas de resultados, muitas vezes difíceis de serem alcançados. Ao avaliarmos os resultados, podemos constatar que o paciente entendeu o que é importante para o profissional no tratamento ortodôntico, isto é, a melhora da estética e da função, simultaneamente.

Entretanto, o profissional, na maioria dos casos, não compreendeu a principal expectativa do paciente. Apesar de afirmar, em um primeiro momento, que espera do tratamento ortodôntico melhoras estéticas e funcionais, tem como principal motivação para realizar o tratamento ortodôntico a melhora da estética. O que é estranho, pois os profissionais foram unânimes em afirmarem que o paciente tem oportunidade, durante a anamnese, de explicar os motivos que os levaram a procurar o tratamento ortodôntico; e $91 \%$ dos pacientes afirmaram terem tido oportunidade de expressar o que os levou a procurarem o tratamento.

A determinação das expectativas do paciente quanto ao resultado do tratamento é de extrema importância ${ }^{16}$.

Calvielli ${ }^{9}$, ao questionar alguns profissionais se a Odontologia é uma ciência da saúde ou a preocupação estética é dominante, afirmou que a maioria optou pela saúde; somente alguns responderam 
saúde e estética. Entretanto, quando questionou os profissionais sobre a motivação que leva os pacientes aos seus consultórios, na sua esmagadora maioria a estética se apresentou como razão principal $^{9}$. Demonstrando que os profissionais entrevistados estavam atentos à motivação que leva os pacientes a realizarem o tratamento ortodôntico.

Neste momento, deve-se considerar que do perfil dos pacientes que compuseram a amostra investigada, quanto à distribuição pelo gênero, a maior parte $(53 \%)$ era de mulheres, gênero no qual a estética é um fator cultural importante.

É evidente que estamos diante de um paradoxo. O profissional oferece saúde e o paciente está interessado em obter estética. Este contrato apresenta um vício na manifestação da vontade, o que faz compreender porque tantos pacientes se mostram inconformados com o resultado do tratamento9.

As pessoas desejam ser aceitas pelos seus semelhantes. Normalmente, quando uma pessoa procura um cirurgião-dentista solicita a estética, tanto por causa do belo como por causa da aprovação externa que necessita, o que tem a ver com sua condição humana ${ }^{21}$.

\section{Informações sobre os aspectos que envolvem o tratamento ortodôntico}

É preocupante a percentagem total de profissionais que garantem o sucesso do tratamento, já que é unânime entre estes a existência de fatores imprevisiveis que podem interferir no desenvolvimento e no resultado do tratamento. Entre estes fatores citam o crescimento, a anquilose, traumas, colaboração do paciente e resposta biológica individual. Sendo assim, quando um profissional assegura a seu paciente o sucesso do tratamento está induzindo-o a realizar o tratamento na certeza de alcançar o resultado desejado, resultado este que muitas vezes não é possível de ser alcançado e o profissional tem total compreensão deste fato.

Os pacientes buscam algum ressarcimento monetário nos casos de erros ocorridos por culpa do cirurgião-dentista, procurando na máquina ju- diciária todo amparo para esta prestação, que muitas vezes é injusta, pois foge ao controle técnico e científico que rege a Odontologia, assim como em qualquer outra área da saúde ${ }^{24}$.

Tanaka ${ }^{25}$ vem afirmar, em concordância com os profissionais entrevistados neste estudo, que o sucesso do tratamento ortodôntico está ligado a fatores relacionados ao próprio organismo, a respostas biológicas individuais em relação à mecanoterapia, além dos fatores subjetivos relacionados à conduta do paciente.

No Código de Defesa do Consumidor o dever de informar representa um dever essencial, básico para a transparência nas relações de consumo. Em seu Art. $6^{\circ}$ diz que são direitos básicos do consumidor: a informação adequada e clara sobre os diferentes produtos e serviços, características, qualidade e preço, bem como sobre os riscos que apresentam ${ }^{4}$. É importante deixar claro que o Código de Defesa do Consumidor, Lei n 8.078/9042 em seus Art. $2^{\circ}$ e $3^{\circ}$ transforma o cirurgião-dentista em fornecedor, o paciente em consumidor e a atividade da Odontologia em serviço prestado ${ }^{4}$.

Os profissionais afirmaram fornecer esclarecimentos aos pacientes sobre a execução do tratamento e seus possiveis desdobramentos. Quanto a está afirmação: apenas $1 \%$ respondeu não ter sido esclarecido e $4 \%$ não responderam a esta pergunta.

Os esclarecimentos sobre o tratamento aos pacientes são realizados de forma verbal por $50 \%$ dos profissionais e por escrito e com assinatura do paciente por $40 \%$ dos profissionais, esta considerada adequada quando não envolve garantias de resultado de tratamento. Porém, $70 \%$ dos profissionais entrevistados afirmaram não possuir em seu prontuário o consentimento livre e esclarecido, documento considerado ética e legalmente apropriado para os esclarecimentos do tratamento e seus possiveis desdobramentos.

Para o advogado Duarte ${ }^{12}$ não basta informar. O paciente tem que entender o que lhe foi transmitido, assim funciona como regra a informação adequada e clara sobre o procedimento ${ }^{12}$. 
A Portaria do ministério da saúde $\mathrm{n}^{\circ} 1286$ de 26/10/93- art. $8^{\circ}$ e $n^{\circ} 74$ de 04/05/94, que trata dos direitos do paciente, diz: O paciente tem direito a informações claras, simples e compreensivas, adaptadas à sua condição cultural, sobre as ações de diagnóstico e de terapêutica, o que pode decorrer delas e a duração do tratamento ${ }^{7}$.

Neste momento, é relevante abordar o assunto duração do tratamento ortodôntico, segunda maior causa de descontentamento em relação ao tratamento ortodôntico, perdendo somente para a insatisfação quanto à evolução clínica do tratamento. Todos os profissionais entrevistados afirmam fornecer um tempo médio de duração do tratamento, que está entre 2 e 3 anos, baseados em experiência clínica. Enquanto a maioria dos pacientes entrevistados relata ter tido como informação uma média de duração de tratamento, apenas para 53\% dos pacientes está entre 2 e 3 anos.

Existem responsabilidades recíprocas entre dentista, sua equipe e paciente. Uma delas é: o tratamento será completado em um período razoável. Observou-se que todos os profissionais concordam que existem fatores imprevisíveis que podem alterar o resultado e o tempo de tratamento e, portanto, existe dificuldade de se prever o tempo de duração de tratamento exato e mesmo uma média de tempo de tratamento deve ser dada com cuidado. Informar os fatores imprevisíveis que podem ocorrer durante o tratamento e, como conseqüência, o aumento dessa estimativa de tempo pode ser uma boa conduta.

\section{Contratos}

Contrato é um acordo de vontades que se realiza entre duas ou mais pessoas, sobre determinado objeto lícito e possível, com fim de adquirir, resguardar, notificar ou extinguir direitos ${ }^{1}$.

Os contratos formalizados entre cirurgião-dentista e o paciente, por mais amplo que seja seu conceito, poderiam ser considerados como contratos atípicos mistos, isto é, aqueles que resultam de uma combinação de certos elementos previstos pela lei e outros que são criados pelas partes.
$\mathrm{O}$ art. 82 do Código Civil Brasileiro estabelece que a validade do ato jurídico requer agente capaz, o objeto lícito e a forma prescrita e não defesa em lei ${ }^{5}$. É importante salientar a manifestação da vontade. $\mathrm{O}$ ideal seria se toda e qualquer relação contratual entre o cirurgião-dentista e o paciente fosse realizada por meio de contrato escrito, a fim de proteger tanto o profissional como o paciente $^{11}$.

Dos profissionais, $70 \%$ realizam algum tipo de contrato, sendo que $50 \%$ dos contratos são de honorários e manutenções. É importante observar que para $60 \%$ dos profissionais o contrato não é parte integrante de seu prontuário.

Pode-se observar uma preocupação por parte dos profissionais quando se trata do aspecto financeiro do tratamento, já que metade destes realiza contrato de honorários e manutenções. O que não pode ser considerado errado, pois a interpretação da legislação confirma que não há necessidade de um contrato por escrito entre ortodontistas e pacientes e, portanto, os direitos e deveres devem ser respeitados, desde a aceitação do tratamento por ambas as partes. Os profissionais tentam obter algum tipo de garantia quanto ao pagamento de seus honorários ao executarem um documento por escrito, o que pode ser considerado apropriado.

Entretanto, aqueles profissionais que realizam contrato por escrito abrangendo outros aspectos do tratamento o fazem de forma "leonina", isto é, abrangendo aspectos relevantes somente para uma das partes, como por exemplo, contratos ressaltando deveres dos pacientes em relação ao desenvolvimento do tratamento.

O contrato entre profissional e paciente não precisa ser escrito. Pode ser verbal e até mesmo tácito. Nessas condições, não será difícil compreender a importância adquirida na condução do esclarecimento do paciente acerca das eventuais limitações sofridas pelo tratamento odontológico ${ }^{8}$.

Quando o cirurgião-dentista aceita alguém como paciente e é por ele aceito, estabelece-se entre am- 
bos um contrato de prestação de serviços. É o que ocorre com a maioria dos profissionais liberais, entre eles o médico e o advogado. A pretendida aquiescência do paciente às condições de tratamento, apondo sua assinatura ao plano a ele apresentado, não tem o poder de afastar, ou de dividir, o ônus da responsabilidade profissional, sendo esta indivisivele ${ }^{23}$.

\section{Responsabilidade profissional e a relação pro- fissional - paciente}

Rosa $^{22}$ verificou que os processos nos anos $70 \mathrm{e}$ 80 não existiam. Houve um aumento considerável desde o início da década de 90 até os dias de hoje. $\mathrm{O}$ aumento do número de processos nos Estados Unidos refletiu-se no Brasil, nesta última década. Para Rosa ${ }^{22}$, é preciso estudar melhor e orientar mais nossos profissionais sobre esta curva ascendente de processos.

Uma definição apropriada da responsabilidade civil odontológica foi dada por Tanaka ${ }^{25}$, que afirmou que a responsabilidade civil odontológica é uma sanção e dever ético jurídico de ressarcir o dano patrimonial ou moral, fundamentado na certeza da culpa e presente a relação de casualidade entre esta e aquele, em que a causa fora uma omissão ou ação direta ou indireta, praticada pelo cirurgião-dentista no exercício de sua profissão, ou por quem ele é responsável em sua equipe de trabalho.

Os profissionais entrevistados não conheciam os principais conceitos legais da responsabilidade civil manifestados no Novo Código Civil Brasileiro em seus artigos: Art. 186 e Art 1.545.

O que Arbenz ${ }^{3}$ está de acordo, ao definir a responsabilidade profissional do cirurgião-dentista como sendo a obrigação de sofrerem as conseqüências das faltas cometidas no exercício da profissão.

A lei brasileira admite a responsabilidade profissional em seus códigos e normas que asseguram a inteira responsabilidade aos profissionais, médicos, cirurgiões-dentistas e farmacêuticos, frente aos erros cometidos ${ }^{11}$.

Para compreendermos melhor a relação que se estabelece entre o profissional e o paciente, pergun- tamos aos entrevistados o que acreditam ser o mais importante nesta relação, se a capacidade técnica do profissional ou os esclarecimentos prestados sobre o desenvolvimento do tratamento. A capacidade técnica foi assinalada pela maioria dos pacientes e profissionais como fator mais importante no tratamento ortodôntico. Entretanto, Rocha ${ }^{21}$ já alertava que a excelência profissional não depende somente do domínio teórico e prático das habilidades técnicas e artísticas específicas do tratamento. Apesar de toda a tecnologia desenvolvida nos campos da Odontologia, muitas vezes o conhecimento adquirido ainda é desvinculado das inúmeras características naturais do ser humano como, por exemplo, a física, a emocional e a mental. Ao se levar em consideração o relacionamento interpessoal estabelecido entre o paciente e o profissional, este último se propõe a servir e ajudar e, por isso, sua responsabilidade pelo processo e pelo resultado do trabalho é proporcionalmente maior ${ }^{21}$.

É de fundamental importância o bom relacionamento profissional/paciente durante e após o tratamento ortodôntico, além do preparo técnicocientífico e embasamento legal do cirurgião-dentista, tanto para assegurar excelente nível de atendimento e tratamento, quanto para se proteger de eventuais processos judiciais ${ }^{22}$.

O que está de acordo com o resultado de nosso estudo, no qual 90\% dos profissionais responderam que um bom relacionamento com o paciente pode impedir uma ação de responsabilidade civil contra o ortodontista.

O tratamento ortodôntico não depende exclusivamente do ortodontista, mas também da disposição, da motivação e da colaboração do paciente. $\mathrm{O}$ bom relacionamento do profissional com o paciente é imprescindível para o estabelecimento da confiança mútua que influenciará no sucesso do tratamento ${ }^{12}$.

Em nosso estudo, verificamos que o mais importante na defesa de um profissional frente a um processo de responsabilidade civil está na confecção de um prontuário completo, no qual deveria constar a ficha de procedimentos executados, 
com as intercorrências anotadas e com a assinatura do paciente. Procedimento que a maioria dos profissionais entrevistados não executa. Colocando-os em uma situação difícil frente a um possível processo de responsabilidade civil, pois é na documentação odontológica que o cirurgião-dentista procura as provas para a sua defesa ${ }^{8}$. As provas apresentadas pelo profissional são produzidas oportunamente ou não servirão para este fim. Ou seja, se o profissional não adotou o critério de anotar no prontuário detalhadamente as condições em que o tratamento foi realizado, colhendo a assinatura do paciente, haverá, seguramente, extrema dificuldade para evidenciar a conduta clínica adotada.

\section{CONCLUSÕES}

1) A preocupação estética é a principal motivação que leva os pacientes a realizarem o tratamento ortodôntico. Conhecer as expectativas do paciente antes de iniciar o tratamento pode evitar futuros descontentamentos.

2) Esclarecer os pacientes de forma adequada a respeito do desenvolvimento do tratamento e seus possíveis desdobramentos é uma conduta prudente, devido à existência de fatores imprevisíveis que podem, porventura, alterar o resultado e o tempo do tratamento ortodôntico. Sugere-se que os esclarecimentos sejam realizados de forma verbal e por escrito com assinatura do paciente.

3) A literatura e a legislação afirmam que o contrato de prestação de serviço odontológico é um acordo de vontades e pode estar implícito quando o paciente aceita a execução do tratamento ou expressa verbalmente, não necessariamente por escrito. Para os profissionais entrevistados a execução de contratos de honorários e manutenções é um procedimento apropriado, devido à preocupação com o aspecto financeiro do tratamento.

4) A relação profissional/paciente está baseada na capacidade técnica do profissional. Entretanto, manter um bom relacionamento com o paciente pode ser uma conduta que evite um processo de responsabilidade profissional. A adequação do prontuário, com assinatura do paciente, constituise o melhor meio de defesa do cirurgião-dentista.

The relationship between the dentistry professional and patient. The understanding and legal aspects involved in the orthodontic treatment

\begin{abstract}
Aim: the objective of the present research was to investigate the relationship between the dentistry professional and his/her patient in the orthodontic area. The legal aspects involved in the orthodontic treatments were deeply analyzed. Methods: this research was developed using two questionnaires: the first one was submitted to ten orthodontics professionals and the second questionnaire to one hundred patients treated by those ten professionals. Results: the percentile analysis of the patients' reply has demonstrated that the aesthetic aspects are the main reason that impels the patients to the orthodontist's office. All the interviewed professionals believe in the existence of unexpected factors that intervene in both the development and the results of the treatment. Despite the afore mentioned fact $40 \%$ of the professionals assure to the patient a successful treatment. For the majority of the orthodontics professionals the main means against any civil prosecution is the complete and detailed treatment documentation. However, the great majority (90\%) of the professionals interviewed does not possess in their files the executed treatment procedures with the signature of the patient on them. Conclusion: was conclude that the orthodontics professionals has a financial concern, they don't believe that the correct treatment documentation is the main evidence against any civil prosecution, neither worry about to provide complete information for the patients.
\end{abstract}

Key words: Orthodontic. Patient/professional relationship. Legal aspects. Ethical aspects. 


\section{REFERÊNCIAS}

1. ACQUAVIVA, M. C. Dicionário básico de direito Acquaviva. São Paulo: Jurídica Brasileira, 1998.

2. ANTUNES, F. C. M. O cirurgião dentista frente à responsabilidade civil. Disponivel em: <http://www.ortodontiaemrevista. com.br>. Acesso em: 21 abr. 2004.

3. ARBENZ, G. O. Introdução à Odontologia legal. São Paulo: Linográfica, 1959.

4. BRASIL. Leis, Decretos etc. Código de Defesa do Consumidor. São Paulo: Secretaria de Defesa do Consumidor, 1990.

5. BRASIL. Leis etc. Código Civil Brasileiro. São Paulo: Saraiva, 2002.

6. BRASIL. Conselho Federal de Odontologia, 1998. Código de ética odontológica. Rio de Janeiro. Disponível em: <http://cfo. org.br>. Acesso em: 29 ago. 2004.

7. BRASIL. Ministério da Saúde. Portaria n ${ }^{\circ} 1286$ de 26 de outubro de 1993 , art. $8^{\circ}, n^{\circ} 74$ de 4 de maio de 1994. Direitos do paciente.

8. CALVIELLI, I. T. P. Responsabilidade profissional do cirurgiãodentista. In: SILVA, M. Compêndio de Odontologia Legal. São Paulo: Medsi, 1997. p. 399-411.

9. CALVIELLI, I. T. P. Natureza da obrigação assumida pelo C.D. no contrato de locação dos serviços odontológicos. Rev Assoc Paul Cir Dent, São Paulo, v. 56, n. 4, p. 315-318, 1996.

10. CAPELLOZA FILHO, L.; PETRELLI, N. E. Normas gerais para reger as relações de trabalho entre o ortodontista e seu paciente: uma sugestão para uma necessidade inadiável. Ortodontia, São Paulo, v. 26, n. 1, p. 87-91, 1993.

11. DARUGE, E.; MASSINI, N. Responsabilidade profissional do cirurgião dentista em relação às leis civil e penal. In: _. Direitos profissionais na Odontologia. São Paulo: Saraiva, 1978.

12. DUARTE, E. D. Medicina e Direito: prevenir é o melhor remédio. Rev Direito Medi, v. 2, n. 1, 2004.

13. HAAG, C. A.; FERES, M. A. L. Aspectos éticos e legais da Ortodontia no Brasil. Ortodontia, São Paulo, v. 32, n. 2, p. 67-81, 1999.
14. JERROLD, L. Terminating the doctor-patients relationship: abandonment or not? Am J Orthod Dentofacial Orthop, St. Louis, v. 10, no. 6, p. 570-571, 1992.

15. KOUBIK, R.; FERES, M. A. L. Aspectos legais da Ortodontia. Ortodontia, São Paulo, v. 28, n. 2, p. 64-70, 1995.

16. MACHEN, D. E. Legal aspects of orthodontic practice: risk management concepts. Am J Orthod Dentofacial Orthop, St. Louis, v. 97, no. 5, p. 476-477, 1990.

17. MEDEIROS, E. P. G. Ganhar e não perder pacientes. São Paulo: Ed. Santos, 1997. cap. 4, p. 91-104.

18. MENDES, W. B. E.; BONFANTE, G. Fundamentos de estética em Odontologia. Rio de Janeiro: Santos, 1994. p.174-175.

19. OLIVEIRA, I. R. Causas mais freqüentes que levaram os pacientes a reclamarem ao Conselho Regional de Odontologia de São Paulo, em relação à prótese dentária: estudo longitudinal. 1999. Dissertação (Mestrado)-Faculdade de Odontologia, Universidade de São Paulo, São Paulo, 1999

20. PINZAM, A.; VARGAS NETO, J.; JASON, G. P. R. O paciente ortodôntico quanto ao seu grau de informação e motivação e suas expectativas acerca do tratamento. Ortodontia, São Paulo, v. 30, n. 3, p. 40-44, 1997

21. ROCHA, L. M. F. Reabilitação oral: aspecto humano. In: MENDES, W. B. E.; BONFANTE, G. Fundamentos de estética em odontologia. 2. ed. Rio de Janeiro: Ed. Santos, 1996. p. 7-18.

22. ROSA, F. B. Dentista verus paciente ortodôntico: levantamento de problemas jurídicos nas últimas três décadas. J Brás Ortodon Ortop Maxilar, São Paulo, v. 3, n. 13, p. 60-76, 1998.

23. SILVA, M. Aspectos éticos e legais do exercício da Odontologia. In:__. Bases para Endodontia. 1998. p. 365-375.

24. SIMONETTI, F. A. A responsabilidade civil do cirurgião-dentista. Rev Assoc Paul Cir Dent, São Paulo, v. 53, n. 6, p. 449-451, 1999.

25. TANAKA, E. Responsabilidade civil do cirurgião dentista: obrigação de meio ou de resultado? In: HIRONAKA, G. M. F. N. Direito e responsabilidade. Belo Horizonte: Del Rey, 2002. p. $237-286$.

26. TERRA, M. S.; MAJOLO; M. S.; CARILLO, V. E. B. Responsabilidade profissional, ética e o paciente em Ortodontia. Ortodontia, São Paulo, v. 33, n. 3, p. 74-85, 2000.
Endereço para correspondência

Ricarda Duarte da Silva

Rua Ten. Cel. Manoel Miguel Ribeiro, $n^{\circ} 56$

CEP: 80.520-090 - Curitiba /PR

E-mail: ricarda@usp.br 